\title{
Aa. Vv., «Bulletin de la Société Chateaubriand»
}

\section{Aurelio Principato}

\section{(2) OpenEdition}

\section{Journals}

\section{Édition électronique}

URL : http://journals.openedition.org/studifrancesi/34827

DOI : 10.4000/studifrancesi.34827

ISSN : 2427-5856

\section{Éditeur}

Rosenberg \& Sellier

\section{Édition imprimée}

Date de publication : 1 novembre 2005

Pagination : 428-429

ISSN : 0039-2944

\section{Référence électronique}

Aurelio Principato, «Aa. VV., «Bulletin de la Société Chateaubriand»», Studi Francesi [En ligne], 146 (XLIX | II) | 2005, mis en ligne le 30 novembre 2015, consulté le 19 avril 2021. URL : http:// journals.openedition.org/studifrancesi/34827 ; DOI : https://doi.org/10.4000/studifrancesi.34827

Ce document a été généré automatiquement le 19 avril 2021.

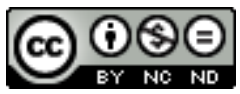

Studi Francesi è distribuita con Licenza Creative Commons Attribuzione - Non commerciale - Non opere derivate 4.0 Internazionale. 


\title{
Aa. Vv., «Bulletin de la Société Chateaubriand»
}

\author{
Aurelio Principato
}

\section{RÉFÉRENCE}

AA. VV., «Bulletin de la Société Chateaubriand», nouvelle série nº 45, 2003, pp. 255.

1 Après les travaux issus de la $C_{L V}^{\circ}$ réunion de la Société (pp. 6-71), à caractère biographique (la présence du cheval dans la vie et l'œuvre, G. GUILLOTEL) ou consacrés à des contemporains, Barante (A. DENIS), le comte Ferrand (G. BERGER) et Chênedollé (J. DUBU), ce numéro volumineux contient les actes du colloque du Bicentenaire du Génie du christianisme (Institut catholique de Paris, 14-15 novembre 2002).

2 Un premier groupe d'articles concerne la pensée du Génie et l'héritage dont elle est redevable. Le Dictionnaire philosophique de Voltaire est le premier adversaire visé (S. MENANT, pp. 74-80): son style polémique, son caractère fragmentaire alphabétique, adapté à un public frivole, permettent au philosophe d'être «tout à fait exact et merveilleusement infidèle», selon la «technique du réflecteur», comme dira Auerbach, et s'opposent à la cohérence et à l'harmonie du système métaphysique recherchées. À l'apport de la science allemande (J. DAGEN, pp. 81-92) Chateaubriand répond par la résorption du temps ponctuel dans un présent absolu, par une vision symbolique de la nature concevant plus l'immanence du divin que sa transcendance. La conciliation de l'idée de progrès et de la foi en la Providence s'étend de l'Essai sur les Révolutions au Génie, plus tard aux Études historiques de 1830 (G. BERGER, pp. 93-110). La référence biblique (H. THURSTON, pp. 164-169) - notamment la vexata quaestio de la chronologie de la Genèse, l'abandon du critère scientifique au profit d'une lecture esthétique s'efforce d'expliquer le présent de la Révolution, donc de donner un sens à l'Histoire. Tout en conservant des accents rousseauistes dans le contact avec le paysage ou le sentiment de l'existence, Chateaubriand se serait plus inspiré de l'abandon à l'évidence 
du sentiment prôné par Ballanche que de la profession de foi du vicaire savoyard (J. ROUSSEL, pp. 140-147).

D'autres contributions confrontent les idées de Chateaubriand à celles de personnalités en vue en 1802. La Harpe, à qui il consacre une notice nécrologique en 1803 dans Le Mercure de France, demeure cependant bien éloigné, dans son pamphlet sur Le Fanatisme dans la langue révolutionnaire (1797), de sa conception de la restauration du christianisme (J.-P. CLEMENT, pp. 148-157). Bonald et sa Législation primitive, plus proche sur la «réciprocité de l'art et de la société» en faveur de la régénération religieuse, reste soumis à la loi morale plutôt qu'à l'exaltation des passions (G. GENGEMBRE, pp. 170-174). Le Génie, par l'intermédiaire de Frayssinous à Saint-Sulpice, pourrait avoir influencé l'Essai sur l'indifférence de Lamennais, même si la destruction révolutionnaire de l'enseignement théologique entre-temps l'oriente plutôt vers des nécessités d'ordre sociologique qu'en une tension «verticale» de la pompe du culte exaltée par Chateaubriand (B. HEUDRE, pp. 175-182). Mercier, avec sa «théo-philanthropie» exprimée d'un vocabulaire énergique dans Mon Bonnet de nuit, ressent la nouveauté de ton d'Atala qui partage sa perspective esthétique fondée sur l'enthousiasme et la confiance en le «moi profond» (J. C. BONNET, pp. 111-122). Ginguené, le publiciste de La Décade philosophique, attaque en revanche ses erreurs en musique et littérature italiennes, oppose un idéal utilitariste, issu de la sensibilité diderotienne, aux valeurs prônées dans le Génie, reproche le rôle joué dans son merveilleux chrétien par l'imagination et le mystère comme sources de vérité, vu son propre refus rationaliste de la fusion entre religion et morale (B. DIDIER, pp. 158-163).

Enfin, dans un ensemble de communications plus orienté sur le style, le devoir artistique «de choisir et de cacher» dans les descriptions matérielles que s'impose Chateaubriand est associé à une quête du «beau idéal», excluant la laideur moderne, mais alliée à une recherche d'historicité qui «se veut tout à la fois dans et hors l'histoire» (B. DEGOUT, pp. 215-222). Pourtant la tonalité funèbre du Génie recourt (selon A. VERLET, pp. 183-190) à des images de décomposition morbide qui rattachent Chateaubriand à la modernité, quoiqu'il accorde sa préférence à un sublime littéraire d'origine médiévale épique en «dialogue avec le sacré» qui fait du christianisme la véritable révolution de l'humanité (F. BERCEGOL, pp. 191-199). Malgré la rareté des pages consacrées aux compositeurs et à leurs œuvres, la fascination de la musique s'intègre à plein dans la poétique de l'auteur, par le mécanisme des sensations, les notions d'harmonie et de mélodie, l'aspect «symphonique» de son lyrisme moderne (J.-M. BAILBE, pp. 208-214). Une lecture augustinienne de l'Énéide fournit à Chateaubriand des métaphores anciennes pour exprimer son épopée religieuse et mélancolique, les vacua atria ou inania regna, cités en latin dans le Génie, s'accordant parfaitement à l'évocation d'un monde bouleversé par la Révolution (Е. TABET pp. 123-132). Une «évidente communauté d'intention et de stratégie» le lie encore à Louis Racine l'auteur de $L a$ Religion (1742), «le fondateur de la poésie descriptive en France», dont il utilise paradoxalement les thèmes exprimés en une versification «fatiguée» au service d'une prose imprégnée de transcendance (É. GuITTON, pp. 133-139). Le Génie semble aussi «assimiler l'effet esthétique d'Ossian», à la position païenne ambiguë, avec celui des ruines chrétiennes, Atala christianisant son monde celtique, en une dimension politique donnée au barde écossais que Van Tieghem a peut-être négligée (C. SMETHURST, pp. 200-207). 
5 La conclusion (A. MICHEL, pp. 223-224) souligne l'envergure intellectuelle atteinte par Chateaubriand, dans un ouvrage qui «bénéficie de toutes les rencontres» et devance l'entreprise systématique de Balzac. Ce colloque contribue à montrer une fois de plus la portée européenne du Génie du christianisme, que Marc Fumaroli (Chateaubriand, Poésie et Terreur, Paris, De Fallois, 2003) a éclairé depuis dans ses rapports avec la tradition et le néoclassicisme de Winckelmann. Les renvois à Mme de Staël ou Constant, ainsi qu'à l'idêalisme allemand ou à la dimension politique de la littêrature, suggèrent à quel point la comparaison avec la pensée esthétique élaborée au sein du groupe de coppet comme dans d'autres pays mérite d'être poursuivie. 